\title{
A fraternidade como forma de governo: a novela de José e as costuras literárias de Gênesis 37-50
}

\author{
The fraternity as a form of government: Joseph's novel \\ and the literary seams of Genesis 37-50
}

\section{La fraternidad como forma de gobierno: la novela de José y las costuras literarias de Génesis 37-50}

João Batista Ribeiro Santos*

Fernando Ripoli**

\begin{abstract}
RESUMO
Teremos como objetivo em nosso artigo descrever as formas de governo na novela de José (Gênesis 37-50); para isso, apresentaremos as costuras literárias e históricas que o texto novelístico nos apresenta. Abordaremos as categorizações de governo, a saber, reinar e dominar, temáticas características de quase toda a novela, cujo ambientação egípcia é uma retroprojeção em perspectiva realizada no século VI e incorporada à história dos patriarcas entre os séculos V-IV.

Palavras-chave: História social; literatura antiga; colonialismo; memória cultural; antigo Oriente-Próximo.
\end{abstract}

\begin{abstract}
We will aim in our article to describe the forms of government in the novel of Joseph (Genesis 37-50); for this, we will present the literary and historical seams that the novelistic text presents to us. Government categorizations will be addressed, namely, reign and dominate, themes characteristic of almost the whole novel, whose Egyptian setting is a rear projection in perspective realized in the sixth century and incorporated into the history of the patriarchs between the fifth and fourth century.

Keywords: Social history; ancient literature; colonialism; cultural memory; ancient Near East.

\section{RESUMEN}

Tendremos como objetivo en nuestro artículo describir las formas de gobierno en la novela de José (Génesis 37-50); para ello, presentaremos las costuras literarias e históricas que el texto novelístico nos presenta. Se abordarán las categorizaciones de gobierno, a saber, reinar y dominar, temáticas características de casi toda la novela, cuya ambientación egipcia es una retroproyección en perspectiva realizada en el siglo VI e incorporada a la historia de los patriarcas entre el siglos V-IV.

Palabras clave: Historia social; literatura antigua; colonialismo; memoria cultural; Próximo Oriente antiguo.
\end{abstract}

\footnotetext{
* Professor doutor da Escola de Teologia da Universidade Metodista de São Paulo (Umesp). E-mail: joao.ribeiro@metodista.br

** Professor-tutor da Escola de Teologia da Universidade Metodista de São Paulo (Umesp), doutorando em Ciências da Religião. E-mail: fernando.ripoli@metodista.br
} 


\section{Introdução}

Estamos diante de uma novela onde a ascensão de José pode ser compreendida como um produto de fantasia (DOBBERAHN, 1988). José como escravo, é um argumento que pode ter sido construído ao longo de vários séculos entre populações mediterrâneas, com as memórias passando por desenvolvimentos desde o Egito. Os postulados de Friedrich Erich Dobberahn são elementos iniciais para construirmos hipóteses concisas em relação à novela de José. Inicialmente apresentaremos as funções ideológicas do texto novelístico, analisando as argumentações de Luca Mazzinghi (2017), que sugere hipoteticamente a existência de alguma historicidade na construção do enredo.

As considerações de migração, rapto e comercialização de seres humanos nos ajudarão a sintetizar e interpretar acerca do grito da mulher de Potifar, o mesmo pode nos indicar uma situação completamente diferente daquelas argumentações tradicionalmente romanescas. O comércio extorsivo em tempo de escassez da produção de alimentos, sob a direção de José, torna-se o objeto central para compreendermos a sociedade. Identificaremos na narrativa novelística que José exerce os papeis de herói salvador ${ }^{1}$ e de tirano.

\section{As costuras literárias}

O início indica um cabeçalho genealógico. Narra-se: "Estas [são] gerações de Jacó" ('ellleh tōldôt Ya ăqōob ...). . Por distanciar-se historicamente das realidades do Egito, as narrações aproximam-nos dos ambientes vivenciais das comunidades do judaísmo antigo. São descritas na novela diversas observações sobre empreendimentos sociais e escravidão com validade tanto para o Egito quanto para o Levante.

[...] a história de José se atém a algumas condições "históricas" sob as quais tal fabulosa ascensão pode ser compreendida não apenas como puro produto de fantasia, mas entra perfeitamente em cogitação como uma possibilidade "historicamente" dada. Não é de se excluir que o destino do escravo José, na forma como é narrado em Gênesis 37-50, reporta-se em traços gerais a acontecimentos ocorridos nos séculos XIV a XII a.C. na Síria e na Palestina, pressupondo, nos capítulos que se desenrolam no próprio Egito, um desenvolvimento religioso e social especial do Egito. As consequências deste desenvolvimento especial se manifestam, durante a $7^{\mathrm{a}}$ e a $8^{\mathrm{a}}$ (2155-2134 a.C.) e durante a $18^{\mathrm{a}}$ e a $19^{\mathrm{a}}$ dinastias do Egito (1552-1186 a.C.), nas formas de crises de Estado e revoluções sociais (DOBBERAHN, 1988, p. 27).

\footnotetext{
Para a comunidade israelita do período posterior ao exílio babilônico.

2 Gênesis 37.2. Como informação, as transliterações e traduções de textos da Bíblia hebraica neste artigo foram realizadas a partir da obra editada por Karl Elliger e Wilhelm Rudolph (1997).
} 
No início da novela de José podemos notar uma pequena introdução, ${ }^{3}$ nesta introdução nos é apresentado pelo redator a função ideológica ${ }^{4}$ de todo o texto novelístico, parece-nos ser proporcionado através da novela uma história de família, a vida do patriarca Jacó, seus filhos e sua mulher preferida que já estava morta. ${ }^{5}$

A narrativa novelística situa-se na obra historiográfica de Êxodo 2-2Reis 25, com redação inicial na época do exílio babilônio no contexto da historiografia deuteronomística, baseado na conclusão "babilônica" de 2Reis 25, diferente da conclusão persa do cronista (2Crônica 36). Alguns aspectos literários, salientados por Konrad Schmid (2013, p. 153), fornecem evidências de inclusões editoriais, tais como a coerência linguística, o esboço histórico da grandeza social Israel a partir do Egito, como quem desconhece as tradições patriarcais, e a dependência de antigos acontecimentos do período da monarquia para a elaboração de seus eventos fundantes.

A novela apresenta vários grandes temas bem distinguíveis no seu enredo, com encenações biográficas do protagonista: o conflito entre José e seus irmãos, a aparição e ascensão dele no Egito, e a reconciliação entre José e seus irmãos.

A atual função da história de José dentro do Pentateuco reside na explicação de como os antepassados do que será Israel chegaram ao Egito, para que o povo depois pudesse sair dali. Entretanto, a história não foi escrita para esta finalidade, o que já mostra o fato de, em Gênesis 50, Israel se encontrar em Canaã por ocasião do enterro de Jacó, sendo deslocado mais uma vez para o Egito só por um versículo adicional (50.14). Acrescente-se a isso que a história de José, diante da apresentação subsequente do êxodo, constrói tensões que se referem basicamente à imagem de faraó e de Israel, de modo que em Exodo 1, inicialmente, a história de José necessita ser neutralizada narrativamente (v. 6-8) (SCHMID, 2013, p. 156-157).

A perícope de Gênesis 37.28,36 apresenta-nos um conflito na descrição de quem realmente vendeu José para Potifar. Por uma glosa redacional, tomamos conhecimento acerca da chegada dos midianitas, são eles que retiram José da cisterna para vendê-lo aos ismaelitas. Para Jean-Louis Ska,

a história de José distingue-se também do restante do Pentateuco do ponto de vista literário. A arte narrativa é mais refinada, o estudo da psicologia, mais profundo, e a

\footnotetext{
3 Gênesis 37.2-11.

4 A função ideológica da novela em nossos apontamentos está relacionada ao mito/ficção judaico (a) construído (a) no período do pós-exílio babilônico para justificar as ações do presente (SAPIR-HEN; BEN YOSEF, 2013, p. 284).

5 Gênesis 35.19-20.
} 
composição do relato, mais elaborada. Não estamos mais exatamente no mundo dos relatos populares, mas em um âmbito mais próximo das grandes escolas literárias do tempo (SKA, 2015, p. 44).

Se realmente Ska estiver correto em sua proposição, estamos próximos das escolas literárias neobabilônias ou no período persa. Nesse caso, o destino de José, de fato, descreveria a vida de um judeu da diáspora, fora da terra prometida. A história, portanto, não apenas tornou obsoleta a assim chamada "teoria das fontes" como também projeta, justificadamente para as migrações de povos mediterrâneos, uma imagem positiva do Egito. Schmid chega a denominá-la de uma historiografia "antideuteronomista". Essa construção da realidade na diáspora no sul do Levante e em terras abaixo do rio Nilo pode ser refletida à luz da onda migratória para o Egito no final do século VII e início do século VI, como fuga do assédio e invasão das guarnições babilônias em Judah (Yahûdāh).

Sendo que, para o período posterior ao exílio na Babilônia, a justificativa presta apoio àqueles que decidiram permanecer naquele país, agora controlado por dinastia persa, na contracorrente da unidade étnica imposta pelos novos assentados na colônia de Judah (Yahûd). Além da forma pedagógica com que trata os irmãos (mais adequada à estrutura de parentesco), a narração do textus receptus publica o seu desacordo com a didática punitivista do sacerdotado.

Olhar a reconstrução de ambientes domésticos e as reorganizações familiais, a rememoração do culto com novas funções traditivas e as fundações normativas na perspectiva da consanguinidade requer técnicas de gestão. A redação de Gênesis 39-41, mesmo com a recepção redacional do capítulo 38 - refletido no capítulo 44 -, cumpre a função de prover com exemplos os novos administradores da colônia. Com relação à história de Tamar, Speiser (1964) afirma que a mesma está relacionada à inserção de narrativa para preencher o espaço entre o desaparecimento de José e o seu reaparecimento no Egito. Por outro lado, a nosso ver, para a reorganização das famílias deve haver critérios de pertença conjugal, restrição à cobiça ainda que haja tolerância por parte de quem sofrer o vilipêndio, condição para a confiança mútua irrestrita inclusive considerando a autoridade pessoal e a divisão das atividades sociais na nova comunidade.

$\mathrm{Na}$ verdade, a cada ato de violência o silêncio constitui-se como atitude exitosa para superar o conflito estabelecido ou o infortúnio sofrido. Com relação a José:

O silêncio que José opõe à acusação da mulher de seu amo poderia revelar um homem que se tornou justo e sábio, e que, ao contrário dos outros personagens da narrativa, não 
se subtrai a rechaçar o mal, mesmo quando ele o está sofrendo. Ele não tenta vingar-se dos outros por causa do sofrimento que o atingiu, mas busca detê-lo dentro de si, em vez de lhe dar chances de proliferar (WÉNIN, 2011, p. 105).

Para que a comunidade subsista diante de adversidades geradoras de conflitos (a qualidade do solo, a resistência do assim chamado povo da terra, a política imperial persa, a divergência interna quanto a prioridades, a forma de culto, os processos de construção de identidades como oposição às culturas locais etc.) é importante priorizar a presença de Yahweh/Adonai como única instância decisória. Isso em qualquer circunstância e condição humana. ${ }^{6}$ Ainda aqui, o Egito mantém-se como modelo regional de prosperidade para os novos empreendimentos no Levante, nos quais a dependência da população a Yahweh é inquestionável, assim como a avaliação positiva de líderes estrangeiros. Nas costuras literárias, temos:

A avaliação basicamente positiva daqueles que estão fora da comunidade de fé, algo típico do Gênesis. O incidente com a esposa de Potifar indica o potencial para o uso indevido do poder por aqueles em posições elevadas. No entanto, em Gênesis, o autor vê o poder político tanto quando José está no poder quanto quando ele não está, muito mais positivamente. Em vez de espelhar depois Israel, esse aspecto da história fornece aos governantes um ideal pelo qual lutar (FRETHEIM, 1994, p. 612).

Realmente, a perícope nos proporciona um drama social protagonizado pela mulher de Potifar. O brado dessa mulher interpreta um grito de abuso de poder sobre as categorias escasseadas socialmente, refletida na figura de José (o escravo) ou das pessoas marginalizadas no período egípcio ambientado ou nas colônias persas. No entanto, será necessário ler a novela por ao menos duas perspectivas historicizantes.

\section{Articulações ideológicas}

\section{Por um perspectivismo egípio}

A princípio, considerando a situação vital do judaísmo antigo, está claro, portanto, que a base material requererá uma rede composta por famílias, necessariamente com duplo vínculo: cultural, o culto a Yahweh, e econômico. Em território com escassez de água doce, desertificação e com poucas alternativas agriculturais, a fraternidade será imprescindível para que todos adquirem a suficiência nutricional. Quanto ao que diz respeito à agricultura de subsistência - não necessariamente da escassez -, a novela problematiza os usos da produção; exige-se técnicas para a gestão da economia.

\footnotetext{
Assim, Gênesis 39.1-8, 10-19, 20-23.
} 
Temos, entretanto, a crítica à apropriação tanto dos meios de produção quanto do que fora produzido. Em Gênesis 41.46-57, José organiza o trigo (tributo) em todas as cidades do Egito e na sequência impõe o seu poder como administrador. Resta às pessoas, para sua sobrevivência, comprar o trigo controlado por José. Desta forma os povos do sul do Levante foram submetidos à dominação egípcia, quem não comprasse o trigo com José morreria de fome. Instaura-se no Egito uma forma sistemática de escravização por meio da apropriação dos instrumentos agrários (ferramentas, mão de obra, terra agricultável etc.) e do controle das estações distribuidoras.

Depois do estabelecimento de Jacó no Egito, a narrativa é interrompida $(47,13)$. Aqui retomamos ao princípio, quando José estava organizando a política agrária do Faraó, antes do encontro com seus irmãos (41,57). Isto é, poderíamos muito bem juntar 41,57 como em 47,13-56, pois aqui José conclui o que havia começado lá. Gn 47, 13-26 é, sem dúvida, o maior modelo de extorsão presente na Bíblia. Através da imposição do tributo, ou seja, da quinta parte de toda a produção, José passa às mãos do Faraó todo o país $(47,20 \mathrm{~b})$. Inicialmente, apropria-se de todo o dinheiro em troca de cereais que ele havia usurpado do povo $(47,14)$; depois quando esgotou o dinheiro, José exige o gado (47,15-17); terminando o dinheiro e o gado, José se apodera das terras (47,18-20); e, finalmente, se assenhoreia das pessoas, reduzindo-as à servidão $(47,21)$. Somente fica intocáveis as terras e os bens dos sacerdotes (47,22-26c). Este texto concentra toda a ideologia de fundo que tenta justificar o domínio de José sobre seus irmãos: dois sistemas em conflito, o monárquico e o tribal (KAEFER, 2005, p. 67).

José é soberano, governador, administrador e principalmente um tirano. ${ }^{7}$ Obviamente tutelado pelo faraó. Acerca da tirania, Camila Condilo (2009, p. 132) afirma: "De maneira que é possível afirmar que as personagens de reis e tiranos encarnam a figura do herói trágico e que eles são agentes importantes no desenrolar do processo histórico". Cotejado com o nosso objeto de pesquisa, o papel de herói se encaixa perfeitamente. José não apenas dirige as políticas governamentais, mas as utiliza para extorquir a população, levar as pessoas até à categorização de escravos do faraó.

\footnotetext{
É figura do herói trágico e que são agentes importantes no desenrolar do processo histórico (CONDI-

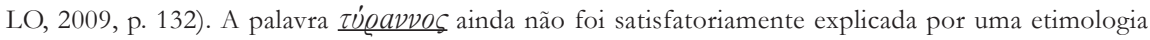
grega, e a conjectura de Boeckh de que era uma palavra estrangeira e veio aos gregos da Lídia ou da Frígia, onde é encontrada frequentemente em inscrições, é extremamente provável (BOECKH, Comment. Ad CIGn. 3438). O significado que a palavra transmitia à mente grega era o de um homem que exercia o poder absoluto e um poder não sancionado pelas ordenanças do estado em que era exercido. Isso é tudo o que é essencial para a noção; todavia, o pensamento filosófico posterior da Grécia, combinado com a experiência histórica real, desenvolveu um acréscimo à concepção - a saber, que a regra dos qú@avvoৎ foi exercida não no interesse dos sujeitos, mas na do governante (BOER, 1997, p. 85). Disponível em: < http://www.perseus.tufts.edu/ > Acesso em: 16 mai 2018.
} 
O governo tirano proporcionado nas narrativas novelísticas de José, leva-nos a identificação o que Jean-Pierre Vernant e Pierre Vidal-Naquet nos apresenta sobre a definição de um tirano no mundo antigo, segundo a concepção do imaginário grego:

O coxear, a tirania, o poder conquistado e perdido, a sequência contínua ou bloqueada de gerações, a sucessão direta ou desviada, a retidão ou os desvios nas relações sexuais, o acordo ou mal-entendido na comunicação dos pais com os filhos e dos filhos entre si, a presença de espírito ou esquecimento -, é porque, no imaginário grego, a figura do tirano, tal como pintada nos séculos V e IV a.C, desposa os traços do herói legendário, ao mesmo tempo eleito e maldito (VERNANT; VIDAL-NAQUET, 1991, p. 71).

Esta categorização de tirano que Pierre Vernant e Pierre Vidal-Naquet nos apresentam pode ser relacionada à figura mítica da novela. Ele carrega os traços de um herói legendário do povo israelita no período posterior ao exílio babilônio. José é o personagem mítico que foi eleito pelo faraó para ser administrador do império.

Eis a fórmula das apropriações: " $E$ disse José ao povo: 'Prestem atenção: eu adquiri a vós hoje e a vossa terra para faraó, a vós e a vossa terra"”. Perspectivamente, o povo agradece José pela escravidão e extorsão:" "E eles disseram: 'Fizeste-nos viver, encontramos graça nos olhos do meu [nosso] senhor e viveremos para faraó". Por obviedade literária, temos a construção de redator judaíta ou, em caso de datação mais recente, judeu:

Nessa época imperava o despotismo e todos os direitos dos cidadãos eram contestáveis, e a ilegitimidade do Poder gerava crise e mais crises e mais crises de instabilidade, algumas em caráter permanente. E nem a religião e a vontade popular legitimavam o Estado que tinha que contar apenas com a energia do Criador (CARLI, 2015, p. 209).

Com efeito, temos um monarca governando e agindo segundo as diretrizes divinas de Yahweh (os sonhos), por meio de instrumentos de dominação opressores. Todas as terras são transferidas ao poder do faraó, com altas taxas de tributação. Destarte, devemos postular que "uma das principais características do modo de produção asiático é a existência de um Estado despótico acima das comunidades aldeãs" (TUNES, 1990, p. 60), pensado como uma das funções da monarquia. Na verdade, com a monarquia desenvolveu-se a urbanização, o comércio de longo curso, a escala de produção agrária e, portanto, a tributação. Desde o início da urbanização e dissolução das comunidades rurais o Estado "se foi erigindo", para usar uma expressão de Cássio Marcelo de Melo Tunes, como agente econômico controlador.

\footnotetext{
8 Gênesis 47.23a.

9 Gênesis 47.25.
} 
Mas o Estado não é um agente abstrato, e mesmo que o consideremos tendo em vista a aristocracia ainda não teremos os grupos sociais. Então, o Estado são a nobreza da corte ou palacial, os escribas, sacerdotados templares, oficiais militares, os funcionários subsidiários do palácio (coletores de impostos, coletores da produção, membros da defesa), grupos que chegam com a urbanização, são burocráticos e constroem a estrutura da sociedade para funções que lhes dizem respeito.

Nesse modelo, as taxações e tributos - tanto coletivo quanto individualizado, tanto agricultural in natura quanto por mão de obra artesã etc. está presente no resultado das atividades sociais desde o início do terceiro milênio, com o excedente da produção do país sempre armazenado pelo Estado, o que incluíam os templos. Por isso, há quem prefira considerar a relação entre o Estado e as comunidades como "escravidão generalizada" (TUNES, 1990, p. 62).

Uma vez atribuída ao Estado o papel de mantenedor, o trabalho livre fica relativizado em função do recolhimento do que é produzido. Essa regra vale para os altamente especializados construtores das tumbas dos faraós. Eles recebiam salários in natura (cereal para pão e cerveja), ocasionalmente muitos outros produtos naturais, roupas e prêmios, eram donos de objetos de luxo e escravos; construíam para si mesmos casas e belos túmulos, mas escavações arqueológicas descobriram que eles residiam em "verdadeiros povoados-prisões, cercados de muralhas com uma só via de ingresso e patrulhados por guardas" (CARDOSO, 2003, p. 28-29). Se assim era com esses trabalhadores de alto nível, aos camponeses a subsistência era possibilitada, desde o terceiro milênio, pela "existência de uma solidariedade coletiva aldeã diante do imposto e das tarefas agrícolas" (CARDOSO, 2003, p. 30).

\section{Por um perspectivismo israelita}

Com os escravos a realidade funda-se mais na dor! Mas abstraindo dos contextos da política egípcia, sobreposto pela escassez generalizada de alimentos, retornemos em direção à colônia judaica. Aí a crítica fica fluida. Nos contextos dos relacionamentos familiais, sobrepõe-se as intrigas comezinhas dos ciúmes. Em um e outro caso a busca por sobrevivência personifica-se como agente aglutinador; na proposição de Westermann (1986, p. 69), "a prosperidade é respondida pela competência, confiabilidade e lealdade inflexível. As circunstâncias simples preparam o caminho para restaurar a paz despedaçada e salvar muitos da fome". Isso dirige-se também à colônia, mas há o problema da religião. Em relação à religião, contra a política cultural legitimadora da exclusão de parte dos membros que constituem a comunidade, 
à guisa de identificação étnica, como notou Terence E. Fretheim (1994, p. 624), "o texto atesta uma notável capacidade de integração da fé javística e outras comunidades e expressões religiosas".

Em adição, à maneira de estímulo, espera-se de quem já praticou injustiças, pois os eventos do passado afixam-se como memórias coletivas, a prática da solidariedade. Portanto, o exemplo publicado como mural do capítulo 44 não projeta a imagem de José, mas a de Judah. ${ }^{10}$ Teologicamente, Judah proporciona a José oportunidade para comunicar a reconciliação. Contra o sofrimento daquele que depende de proteção (hanna'ar), a reivindicação de diretriz autônoma para a sua liberdade. É o que interpreta André Wénin (2011, p. 235) da "súplica de Judah": "Como se, depois de o ter arrancado [Benjamin] de seu pai [Jacó] que o aprisionava em seu afeto, ele [Judah] não queria que outro senhor o prive de sua liberdade".

Para Westermann (1986, p. 137), o capítulo 44.18-34 é descrito por muitos estudiosos como obra-prima da arte retórica e todo o capítulo como o ponto alto da novela. A nosso ver, com os dois capítulos projetados nesse estudo ${ }^{11}$ estão colocadas as possibilidades de construir uma comunidade em cujos parâmetros familiais a verdade e a justiça sejam basilares.

Entende-se: a estrutura da sociedade não precisa ser liderada de forma opressiva!

\section{Conclusão}

Traça-se novos eixos para antigos conflitos. Parece óbvia a relação entre a divindade e a população, mas tomemos na qualidade de uma novidade pelo fato de enfim a presença de Yahweh preencher exatamente o vazio deixado pela monarquia e o rei. O destino da comunidade, por meio da narrativa novelística, segue ligada com as intenções divinas e a elas diz respeito. Mais do que a um determinado capítulo, ${ }^{12}$ todo o enredo da novela depende disso. Claramente, estamos diante de camadas literárias de cunho teológico, entretanto a insistência da presença de Yahweh como promotor da superação de punição injusta ${ }^{13}$ chama a atenção para a incontornável convivência com povos de variados modos de ser, numa região tradicionalmente multicultural.

Atribuir a Yahweh o controle do próprio destino, ao contrário de relegar-se ao abandono das lutas de sobrevivência, enceta a comunidade às buscas por bem-estar social, inserindo as esferas da vida cotidiana nas tradições oriundas da promessa ancestral por terra, atualizada pelos atos divinos em cada evento. O simbolismo da terra deve ser ressaltado na significância de bem-estar, na

10 Gênesis 44.17, 18-34.

11 Gênesis 39 e 44.

12 Claus Westermann (1986, p. 69) faz alusão ao capítulo 39.

13 Gênesis 39.2, 3, 5, 9, 21, 23. 
novela, o salvamento do poço e a libertação da prisão como libertação do exílio babilônio, a emergência política no novo lugar de vivência (Egito) como possibilidade de autonomia político-sacerdotal em Judah (Yahûd).

\section{Referências bibliográficas}

BOER, Roland. Novel Histories: the fiction of biblical criticism. Sheffield: Sheffield Academic Press, 1997.

CARDOSO, Ciro Flamarion S. Trabalho compulsório na antiguidade: ensaio introdutório e coletânea de fontes primárias. 3. ed. Rio de Janeiro: Graal, 2003.

CARLI, Vilma Maria Inocêncio. Resumo analítico da obra científica: O Principe. UCDB Agusvinnus, n. 1, 2015.

CONDILO, Camila. Tirania e pensamento político nas histórias de Heródoto. Codex, Rio de Janeiro, v. 1, n. 2, p. 126-144, 2009.

DOBBERAHN, Friedrich Erich. O destino do escravo José: observações sobre a escravidão no Antigo Egito. Estudos Bíblicos, Petrópolis, n. 18, p. 27-36, 1988. [Gn 37-50].

ELLIGER, Karl; RUDOLPH, Wilhelm (Hrsg.). Biblia Hebraica Stuttgartensia. 5. aufl. Stuttgart: Deutsche Bibelgesellschaft, 1997.

FRETHEIM, Terence E. The Book of Genesis: introduction, commentary, and reflections. In: KECK, Leander E. (Ed.). The New Interpreter's Bible. Vol.1. Nashville: Abingdon Press, 1994, p. 319-674.

KAEFER, José Ademar. A função de Gênesis 49 na narrativa do livro do Gênesis. Ribla, Petrópolis, n. 50, p. 64-69, 2005.

MAZZINGHI, Luca. História de Israel das origens ao período Romano. Petrópolis: Vozes, 2017. SPIR-HEN, Lidar; BEN YOSEF, Erez. The introduction of domestic camels to the southern Levant: evidence from Aravah Valley. Tel Aviv - Journal of the Institute of Archaeology of Tel Aviv University, Tel Aviv, vol. 40, p. 277-285, 2013.

SCHMID, Konrad. História da literatura do Antigo Testamento: uma introdução. São Paulo: Loyola, 2013.

SKA, Jean-Louis. O Antigo Testamento. São Paulo: Paulus, 2015.

SPEISER, E.A. Genesis. Anchor Bible Commentary Series. Nova York: Doubleday, 1964.

TUNES, Cássio Marcelo de Melo. O modo de produção asiático e o Egito antigo. In: CARDOSO, Ciro Flamarion S. (Org.). Modo de produção asiático: uma visita a um velho conceito. Rio de Janeiro: Campus, 1990, p. 55-67.

VERNANT, Jean-Pierre; VIDAL-NAQUET, Pierre. O tirano coxo: De Édipo a Periandro. In: Mito e tragédia na Grécia antiga. São Paulo: Brasiliense, 1991, p.47-72.

WÉNIN, André. José ou a invenção da fraternidade: leitura narrativa e antropológica de Gênesis 37-50. São Paulo: Loyola, 2011.

WESTERMANN, Claus. Genesis 37-50: a commentary. Minneapolis: Augsburg Publishing, 1986.

* Este artigo foi realizado em duas partes, de forma independente, por cada autor. A redação final coube a João Batista R. Santos, assim como as transliterações e traduções de textos da Bíblia hebraica citados.

Submetido em: 14-5-2019

Aceito: 11-6-2019 